\title{
Porosity of Late Paleocene Ornitholithus eggshells (Tremp Fm, south-central Pyrenees, Spain): Palaeoclimatic implications
}

\author{
Mario Donaire* , Nieves López-Martínez \\ Departamento de Paleontología, Fac. CC. Geológicas, Universidad Complutense de Madrid, 28040 Madrid, Spain
}

Keywords:

Fossil eggshells

Ornitholithus

Paleocene-Eocene boundary

Paleocene-Eocene Thermal Maximum

(PETM)

Tremp Formation (Fm)

Pyrenees

\begin{abstract}
A B S T R A C T
Eggshell fragments of ratite type (Ornitholithus, oofamily Elongatoolithidae)-attributed to giant birds-are described from Upper Paleocene deposits in the Pyrenean-Provence region. We study the porosity of a rich Ornitholithus sample from Claret-4 locality (Tremp Fm, Lleida, Spain), closely related to the global warming event which took place at the Paleocene-Eocene boundary (PETM), in order to infer relations between egg conductance, nesting habits and palaeoenviromental conditions.

An egg mass of around $3 \mathrm{~kg}$ is inferred for the large Ornitholithus eggs, in agreement with the values previously estimated by Touraine [Touraine, F., 1960. Oeufs d’Oiseaux de très grande taille dans l’Eocène inférieur de Provence, pp. 783-789], but lower than those obtained by Dughi and Sirugue [Dughi, R., Sirugue, F., 1962. Distribution verticale des oeufs d’oiseaux fósiles de l’Eocène de Basse-Provence. Bull. Soc. Geol. Fr. 7, 69-78]; 0. arquatus group, $8.7 \mathrm{~kg}$ ).

Porosity observed in Ornitholithus eggshells is extremely reduced in comparison to bird eggs and even much more reduced in relation to theropod dinosaurs. Pore number is similar to that of bird eggs but most Ornitholithus pores are exceedingly small (micropores), thus pore radius and total pore area is much lower than in recent birds. Moreover, Ornitholithus micropores lack connectivity between them, thus decreasing functional pore area and permeability. The function of micropores could be related to weight spare, favorable hatching and/or thermal isolation. Ornitholithus eggshells are the most compact of all bird or theropod eggshells studied so far. Consequently, calculated water vapor conductance values in Ornitholithus eggs are in average 8 times lower than that for recent birds. The relation between egg conductance and nesting environment shown in recent birds suggests, in the case of Ornitholithus, an open and extremely dry nest environment. Anomalous compact Ornitholithus eggshells could help to keep eggs' inner relatively-constant temperature and humidity, in the extremely warm and dry palaeoenvironment inferred for the Pyrenean region at the Paleocene Eocene Thermal Maximum.
\end{abstract}

\section{Introduction}

The study of recent and fossil Amniota eggshells provides important data about the phylogeny and physiology of these vertebrates as well as about their nest environment. Studies on fossil eggshell structure have been performed by Mikhailov et al. (1996), Mikhailov (1997), Williams et al. (1984), Grellet-Tinner (2000), Deeming (2006) and Jackson et al. (2008), among others. They show that vertebrate eggshells are constructed under strict genetic and physiological controls, and thus contain phylogenetic, physiologic and palaeoenvironmental information like any other anatomic structure of the Amniota clade. Even when egg-laying taxa are not identified, these remains provide important data to infer, for instance, vertebrate biostratigraphic succession, parental behavior and palaeoenvironmental conditions in nesting sites (Seymour, 1979; Deeming, 2006).
The use of scanning electron microscopy (SEM) in addition to optical and petrographical information for ultrastructural studies on small eggshell fragments allows information to be gained from many fossil sites containing only fragmentary egg remains. In this study we deal with the permeability of fossil bird eggs, which is one of the egg features most strongly connected with the environmental and climatic factors affecting nesting sites (Board and Scott, 1980). Most of the recent bird eggs are relatively exposed during incubation, although protected by adults and nests, and hence experience humidity conditions only slightly modified from the prevailing environmental humidity conditions (Deeming, 2006; Ar 1991, fide Deeming, 2006). Permeability of fossil eggshell fragments can thus provide proxy data for inferring the palaeoclimatic conditions of nest environment (Seymour, 1979; Williams et al., 1984).

We present here a detailed study of eggshell permeability on six samples of eggshells of oogenus Ornitholithus from a large assemblage of eggshell fragments and microvertebrate bones at the Claret- 4 site (Upper Paleocene, Tremp Fm, Lleida, Spain; López-Martínez, 2000), with the aim of inferring palaeoenviromental and palaeoclimatic 


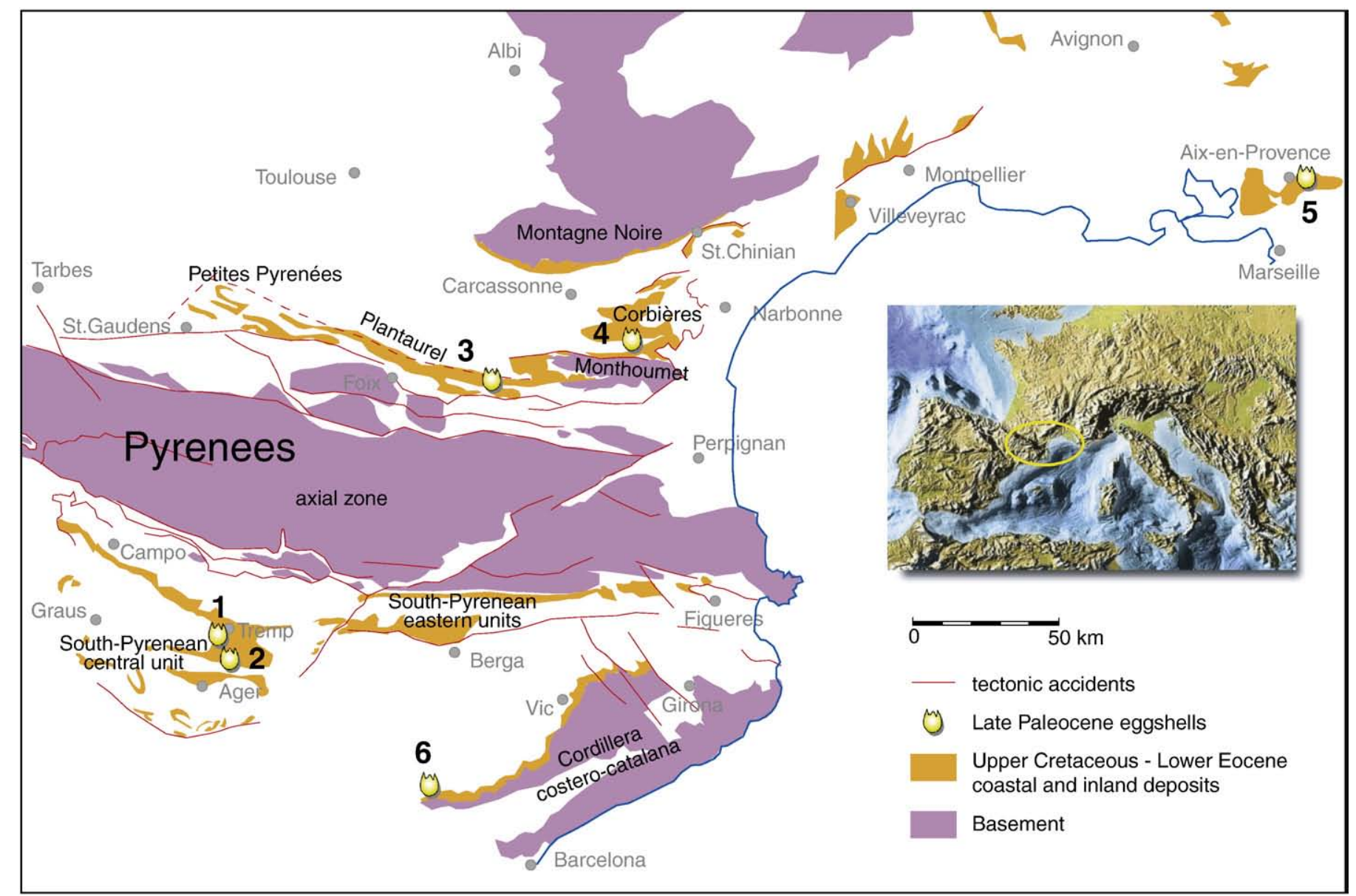

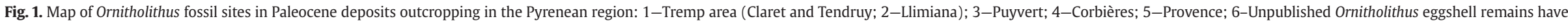
also been found in the Catalonian Coastal Range (Anadon, P., pers. com.). 


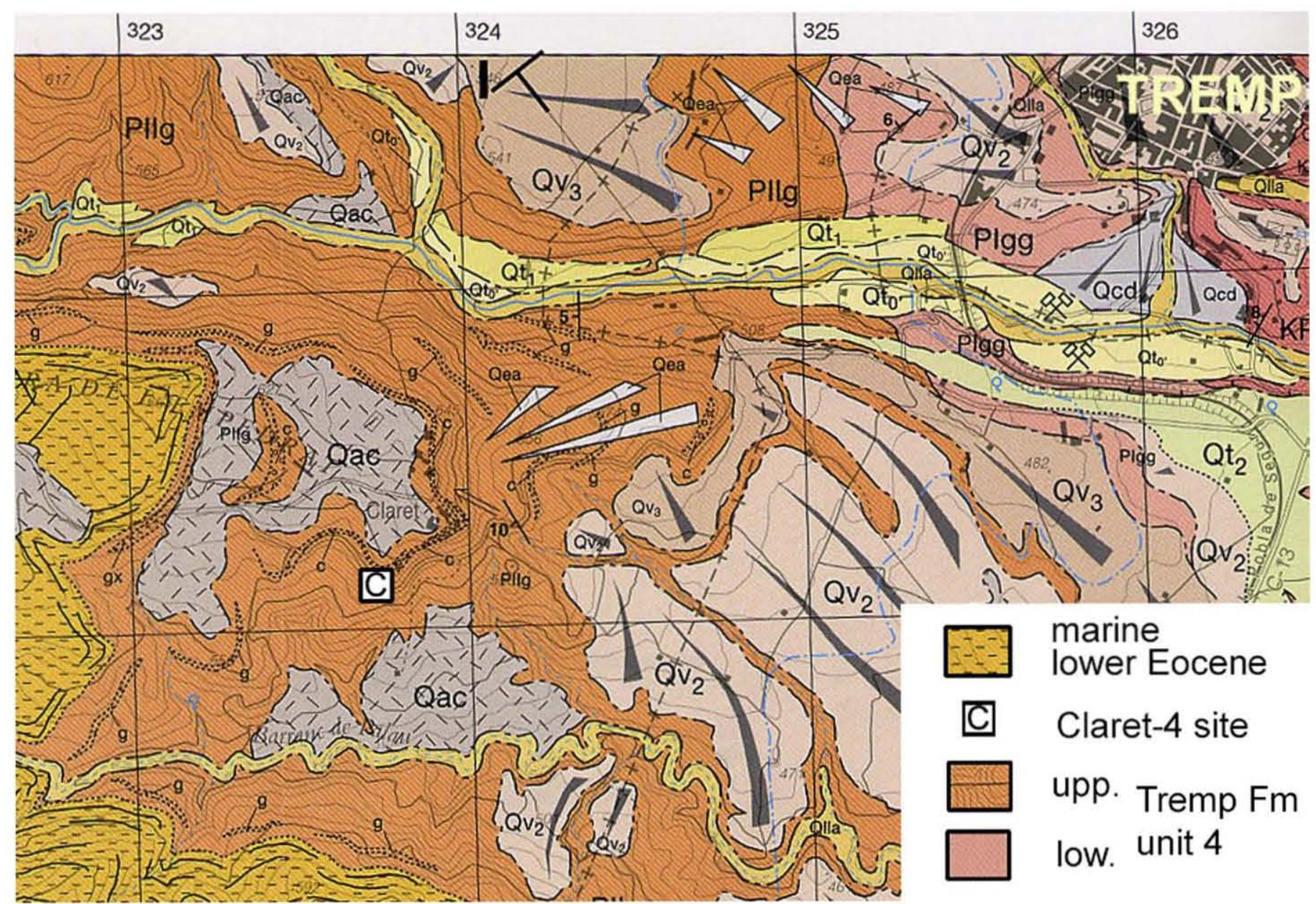

S

TREMP SECTION

$\mathbf{N}$

ESPLUGAFREDA SECTION

NW

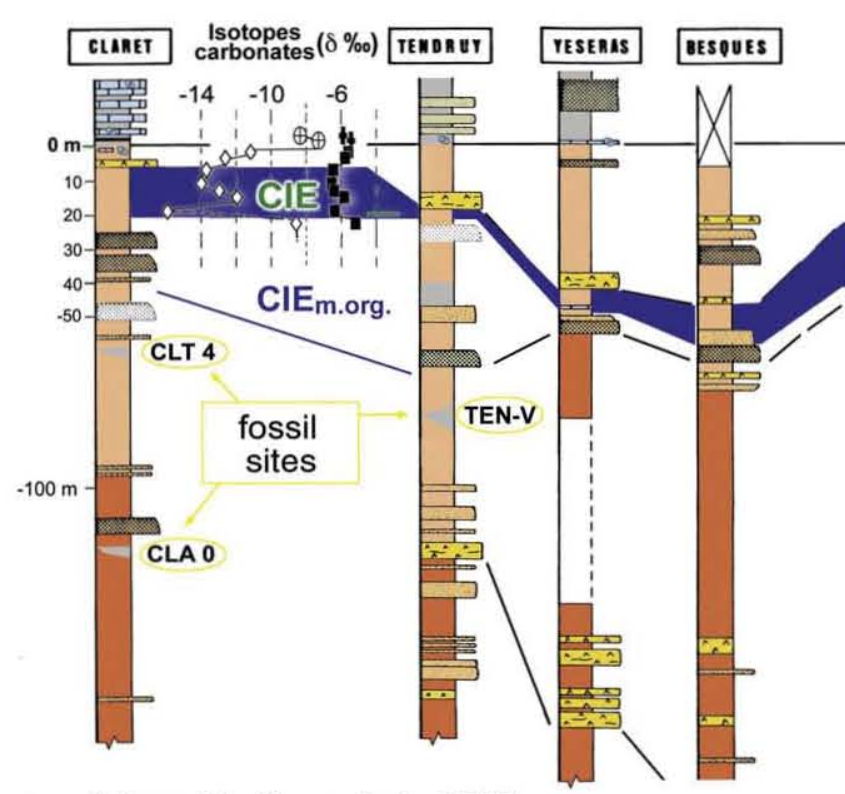

López-Martínez et al., 2006

Domingo et al., 2009

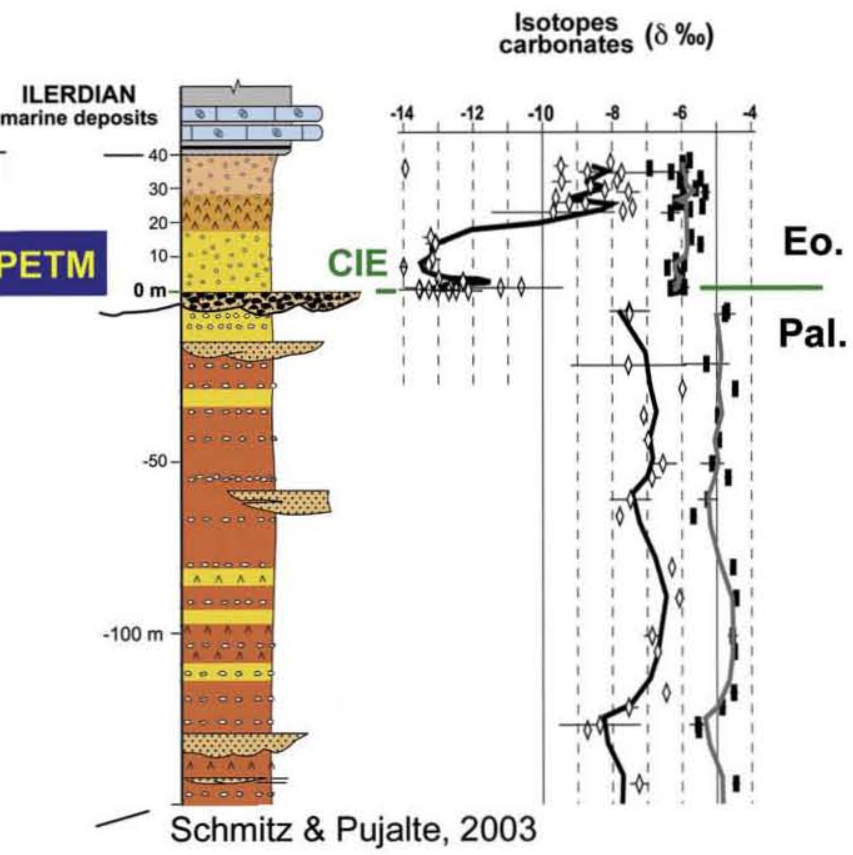

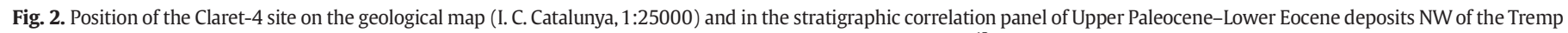

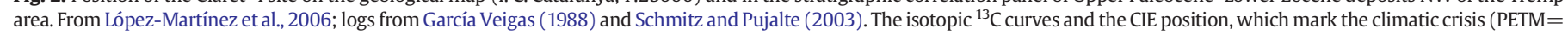
Paleocene-Eocene Thermal Maximum), are shown in the Tendruy and Esplugafreda sections (from Schmitz and Pujalte, 2003, modify following Domingo et al., 2009). 
conditions in the nesting site. Ornitholithus eggshells were first described by Touraine (1960) and Dughi and Sirugue (1962) in Upper Paleocene red beds from Provence (France). Although Ornitholithus eggshells have not yet been found associated with fossil bird bones, they have been referred to giant birds of ratite type with similar eggshell structure. Dughi and Sirugue (1962) assigned Ornitholithus to the oofamily Elongatoolithidae, linked to theropod oviraptorid dinosaurs from the Cretaceous of Mongolia and China (Carpenter, 1999). The confirmed record of eggshells from this oofamily in Upper Paleocene deposits in the Pyrenean-Provence region-far in time and space from its normal occurrence-is thus a surprising finding whose implications will be discussed further.

Ornitholithus has been found in a great number of localities from southern France and NW Spain in similar red beds, dating back to the Upper Paleocene (Fig. 1; Plaziat et al., 1969; Beetschen et al., 1977; Plaziat, 1984). This epoch is well known for experiencing the warmest climatic event of the Cenozoic, known as the Paleocene-Eocene Thermal Maximum (PETM), which affected all ecosystems from deep ocean to land (Zachos et al., 2003). In the Tremp area, the eggshell-bearing site Claret-4, among others, has been dated very close to the beginning of this climatic crisis (Schmitz and Pujalte, 2007; López-Martínez et al., 2006; Domingo et al., 2009). This relatively short climatic episode matches or slightly post-dates the rapid spreading of Ornitholithus eggshells in the Pyrenean realm, suggesting a connection between both events.

\section{Geological setting}

Deposits from the Cretaceous to Paleocene transition in the southcentral Pyrenees contain more than 100 fossil sites including huge quantities of complete dinosaur eggs and eggshells (López-Martínez et al., 2000). Most of them are from Upper Cretaceous coastal deposits of the interfingering Aren and lower Tremp Fms (Sanz et al., 1995; López-Martínez et al., 2000; Díaz Molina et al., 2007). The abundance of fossil eggshell sites from Upper Campanian to Upper Maastrichtian deposits contrasts with its rarity or absence from the uppermost part of Maastrichtian and most Palaeocene deposits. The middle part of the stratigraphic succession, spanning about 9 million years, is barren of fossil eggshells in spite of its lithological facies and thickness, which are similar to those of the eggshell-rich lower part (López-Martínez et al., 2002). Eggshells become widespread again in the uppermost Tremp Fm for a short period near the end of the Paleocene (LópezMartínez et al., 2000). These Late Paleocene eggshells, which constitute the subject of this study, are assigned to the oogenus Ornitholithus and have a size similar to large eggshells from Late Cretaceous, non-avian dinosaurs.

The eggshell remains studied here come from the Claret- 4 site situated in the upper part of the Tremp Formation (Unit 4; LópezMartínez et al., 2006), close to the Claret village near Tremp city (south-central Pyrenees, Lleida Province, Spain). This formation is constituted mainly by detritic materials (red lutites, sandstones and

Table 1

List of the variables used in this work (modified from Deeming, 2006).

\begin{tabular}{lll}
\hline$L$ & Maximum egg length & $\mathrm{mm}$ \\
$B$ & Maximum egg breadth & $\mathrm{mm}$ \\
$M$ & Egg mass & $\mathrm{g}$ \\
$L \mathrm{~s}$ & Shell thickness & $\mathrm{mm}$ \\
$A \mathrm{~s}$ & Total egg surface area & $\mathrm{mm}^{2}$ \\
$A \mathrm{~m}$ & Sampled eggshell surface area & $\mathrm{mm}^{2}$ \\
$n$ & Number of pores in Am & Per sample \\
$P$ & Number of pores greater than $0.0047 \mathrm{~mm}$ radius & Per sample \\
$N$ & Total number of pores & Per egg \\
$r$ & Pore radius & $\mu \mathrm{m}$ \\
$A$ & Mean individual pore area & $\mathrm{mm}{ }^{2}$ \\
$D$ & Pore density & pore number/mm ${ }^{2}$ \\
$A \mathrm{p}$ & Total pore area & $\mathrm{mm}^{2}$ \\
$G_{\mathrm{H} 2 \mathrm{O}}$ & Water vapour conductance & $\mathrm{Mg} \mathrm{H}_{2} \mathrm{O} /$ day*Torr \\
$\mathrm{p} G_{\mathrm{H} 2 \mathrm{O}}$ & Water vapour conductance per pore & $\mu \mathrm{g} \mathrm{H} \mathrm{O} /$ day*Torr*pore \\
\hline
\end{tabular}

Table 2

Formulae used in this work (modified from Deeming, 2006).

\begin{tabular}{|c|c|c|}
\hline (1) & $M=5.48 * 10^{-4 *} L^{*} B^{2}$ & Hoyt (1987) for bird eggs \\
\hline (2) & $D=0.629 * M^{0.105}$ & Deeming (2006) for birds \\
\hline (3) & $r=3.177 * M^{0.230}$ & Deeming (2006) for birds \\
\hline (4) & $G_{\mathrm{H} 2 \mathrm{O}}=A \mathrm{p} /(0.477 * L s)$ & Ar and Rahn (1985). \\
\hline (5) & $N=D * A s$ & Deeming (2006) \\
\hline (6) & $A \mathrm{p}=N^{*} A$ & Deeming (2006) \\
\hline (7) & $A s=4.835 * M^{0.662}$ & Paganelli et al. (1974) for birds \\
\hline (8) & $A \mathrm{p}=0.447 * G_{\mathrm{H} 2 \mathrm{O}} * L \mathrm{~s}$ & Ar and Rahn (1985) for birds \\
\hline (9) & $A p=0.0098 * M^{1.236}$ & Ar and Rahn (1985) for birds \\
\hline (10) & $A \mathrm{p}=0.074 * M^{1.149}$ & Deeming (2006) for theropod dinosaurs \\
\hline (11) & $G_{\mathrm{H} 2 \mathrm{O}}=0.384 * M^{0.814}$ & Ar and Rahn (1985) for birds. \\
\hline (12) & $\mathrm{p} G_{\mathrm{H} 2 \mathrm{O}}=G_{\mathrm{H} 2 \mathrm{O}} / N$ & Deeming (2006) \\
\hline (13) & $\mathrm{p} G_{\mathrm{H} 2 \mathrm{O}}=1.190 * M^{0.050}$ & Ar and Rahn (1985) for birds \\
\hline
\end{tabular}

conglomerates) with intercalation of minor carbonatic and evaporitic levels (see Figs. 1 and 2). The Claret-4 fossiliferous bed consists of a discontinuous gray marly lens intercalated within thick reddish lutites, a few meters below the Claret conglomerate (see below). It bears a rich assemblage of Ornitholithus eggshells, micromammal bones and teeth, charophytes, Microcodium and other fossils (LópezMartínez, 2000; López-Martínez et al., 2006). The assemblage was probably concentrated by a slow water current, since it shows signs of slight transport (size sorting and very small clay pebbles). Fossils are not affected by abrasive processes and several isolated eggshell fragments fit perfectly together as parts of a single egg; thus probably Claret-4 eggshell fragments were derived from nearly entire eggs only slightly transported and mixed with the rest of the fossil assemblage (López-Martínez et al., 2000).

The Claret-4 site is situated few meters below the Carbon Isotope Excursion (CIE) and just below the huge Claret conglomerate (Fig. 2), both interpreted as signals of the climatic crisis at the PaleoceneEocene (P-E) boundary (Schmitz and Pujalte, 2003, 2007; LópezMartínez et al., 2006; Domingo et al., 2009). This event (PETM)dating back to ca. 55 my ago-represents one of the major global environmental perturbations during the Cenozoic epoch (Kennett and Stott, 1991; Zachos et al., 2003; Schmitz and Pujalte, 2007). The event is characterized by a $2 \%-6 \%$ onegative carbon isotope excursion in terrestrial and marine records, rapidly escalating global warming and important floral and faunal turnovers (see Schmitz and Pujalte, 2007 and references therein). The geochemical anomaly related to this crisis has been located in soil carbonates by Schmitz and Pujalte (2003) in two sections correlated to the Claret section just above the Claret conglomerate, about $40 \mathrm{~m}$ above the Claret-4 site (Fig. 2). The time interval between the Claret- 4 site and the CIE-PETM event was estimated at about one-two hundred thousand years by LópezMartínez et al. (2006). Recently, the CIE event has been situated much closer to the Clarte-4 site, based on the isotopic content of the organic matter (Domingo et al., 2009).

The PETM event is linked to important biotic changes which also affected the European terrestrial mammal fauna; among them the acme of the genus Paschaterium (López-Martínez et al., 2006). The rapid spread and extinction of Ornitholithus eggshell-laying birds coincide with the Paschaterium acme and can also be related to the PETM event.

\section{Methods}

Inferences on egg physiology for extinct taxa can be made-even though the eggshell could not be matched to a specific parent taxonby using studies on recent archosaur egg analogs (i.e., crocodiles and birds; Horner, 2000; Deeming, 2006). Estimation of water vapor conductance $\left(G_{\mathrm{H} 2 \mathrm{O}}\right)$ for Ornitholithus eggshells inferred here is based on the methods and data from Deeming (2006) and has been validated with a recent ostrich eggshell. The equations, variables and units employed from this study are summarized in Tables 1 and 2. Number code for equations in the text refers to Table 2 . 
Table 3

Summary of egg mass estimations for Ornitholithus, ostrich and some dinosaur eggs, according to different authors (see text for details).

\begin{tabular}{|c|c|c|c|}
\hline Egg mass & \multirow[t]{2}{*}{ Ref. } & \multirow{2}{*}{$\begin{array}{l}\text { Diameters } \\
(\mathrm{mm}) \\
L^{*} B\end{array}$} & \multirow{2}{*}{$\begin{array}{l}\text { Egg mass } \\
\text { estimations } \\
\text { (g) Eq. (1) }\end{array}$} \\
\hline Sample & & & \\
\hline \multirow[t]{3}{*}{ Ornitholithus } & Dughi \& Sirugue (1962) & $200 * 400$ & 8768 \\
\hline & Touraine (1960) & $240 * 150$ & 2959 \\
\hline & J.P. Villa (2006) & $250 * 150$ & 3083 \\
\hline Ostrich & This work & $150 * 118$ & 1145 \\
\hline Theropoda-Macroelongatoolithus & Deeming (2006) & $390 * 120$ & 3078 \\
\hline
\end{tabular}

Italic figures have been discarded for calculations.

Egg mass $(M)$ is a critical variable for calculations, but complete Ornitholitus eggs have not yet been described from any fossil site. In order to obtain these data, we have made use of the maximum length $(L)$ and breath $(B)$ values of Ornitholithus egg sections published by previous authors (Dughi and Sirugue, 1962; Touraine, 1960; Villa, 2006), subsequently applying regressions between the egg mass and egg size values obtained from recent birds by diverse authors (see Deeming, 2006).

$M=5.48 * 10^{-4} * L^{*} B^{2}$

Estimation by using this equation with respect to the mass of a theoretical ellipsoidal volume only varies slightly (about 3\%). Egg mass estimations obtained are summarized in Table 3 and Fig. 5.
Pore number and size in fossil eggshells can be directly measured from single eggshell fragments, thus allowing direct comparisons among different samples and diverse ootaxa. To determine eggshell porosity, detailed counting of pore number and size was done at different observational scales on six different individual eggshell fragments (AC1-AC6) and then averaged for whole eggs. Micropores have been counted together with macropores, since there is not a clear cut difference between pore types. Pores were considered, counted and measured when the radius was larger than $4.7 \mu \mathrm{m}$. Intercrystal holes named "vesicles" (Mikhailov, 1997)-with a diameter ranging from 0.3 to $1.5 \mu \mathrm{m}$ (average $r=0.75 \mu \mathrm{m}$ )-have been discarded for analysis. The methods used by previous authors to measure porosity in recent bird eggshells, where authors chemically enlarge pore canals for visual counting, are not comparable to those used for fossil eggshells (Ar and Rahn, 1985). In fossil eggshells, pores are filled by cement and cannot be chemically opened, thus they must be counted by direct observation under the microscope, hindering discrimination between functional and non-functional pore canals. Therefore, we have applied the method for fossil eggshells to a sample of a recent ostrich eggshell (AC7) in order to validate the comparison between fossil and recent porosity measures.

Firstly, radial and tangential sections of the studied eggshell fragments showing different external morphologies were photographed with NIKON equipment. Pictures were digitized and measures were
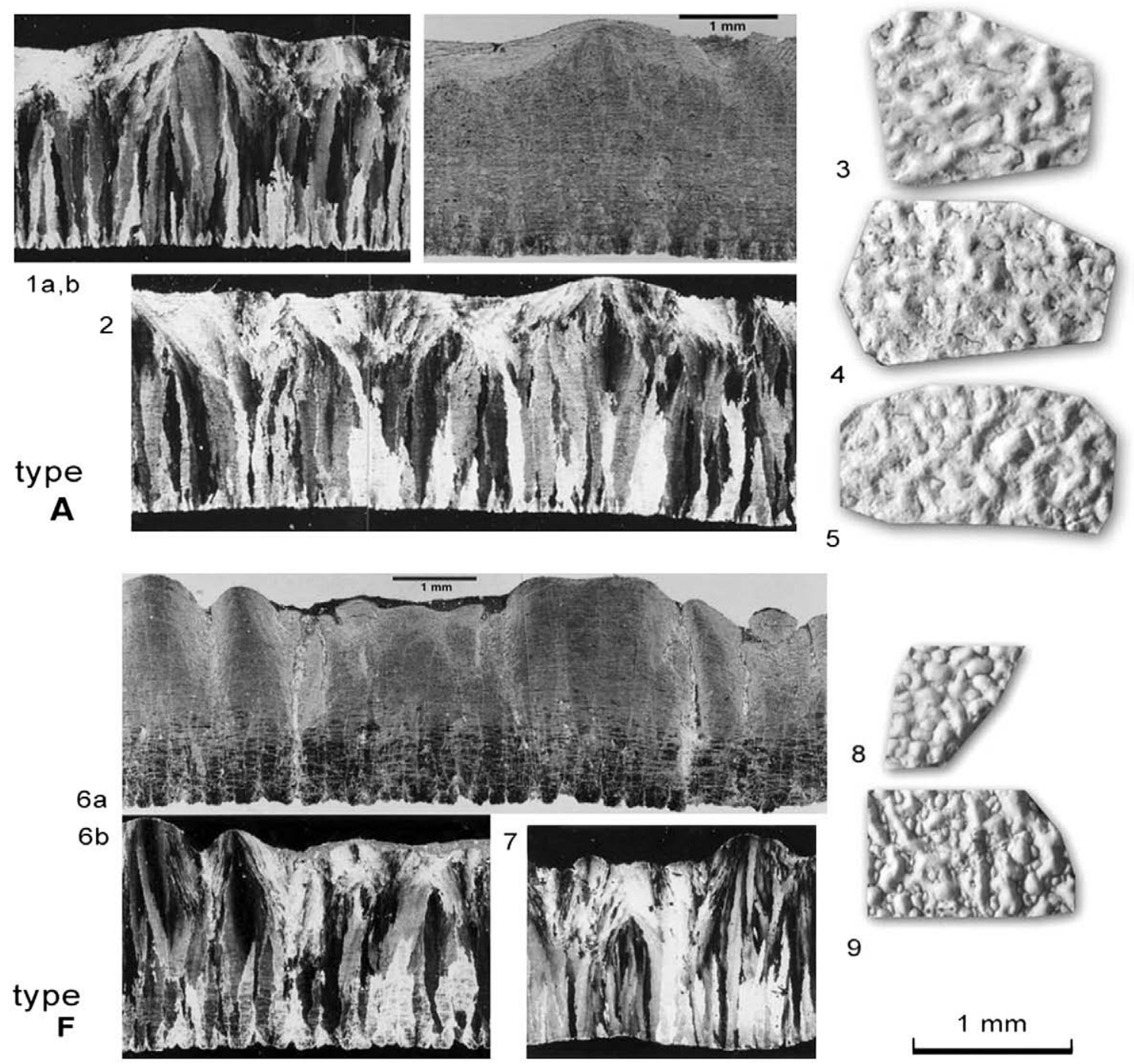

$1 \mathrm{~mm}$

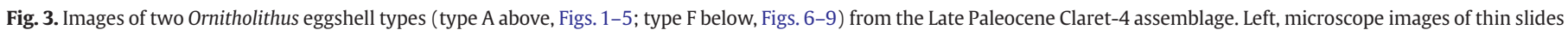
in optical (Figs. 1b, 6a) and polarized light (Figs. 1a, 2, 6b, 7); right, external surfaces of eggshell fragments (Figs. 3-5 and 8, 9); from Kälin (1997). 


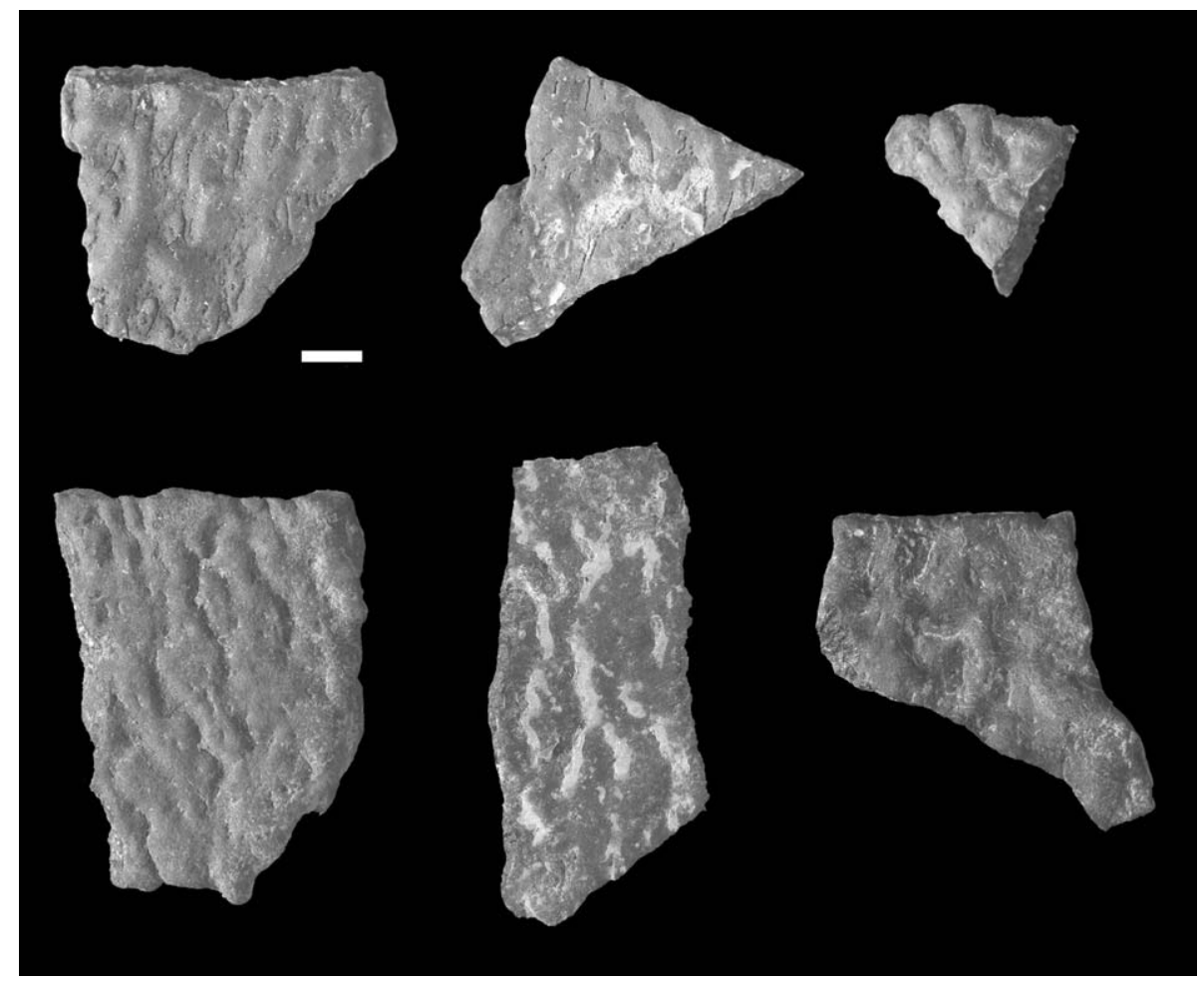

Fig. 4. Studied samples of Ornitholithus eggshells from Claret-4 (Late Paleocene): from left to right and up to down: AC1, AC2, AC3, AC4, AC5, AC6. The graphic scale measures 2 mm.

taken through computer graphic analyses. Eggshell thickness (Ls) was measured in the radial sections at those sites showing maximum thickness, including ornamentation. For pore analysis, we follow the methodology devised by Williams et al. (1984): eggshell fragments are polished with carborundum following tangential planes in three sequential phases, until about $0.5-1 \mathrm{~mm}$ shell thickness is obtained. Total surface of the tangential sections of eggshell fragments (about $10-50 \mathrm{~mm}^{2}$ ) was then scanned and photographed (about 40-60 photos per fragment) with a scanning electron microscope (SEM) by using $\times 300$ magnification. Photographs were then mounted on canvas for total pore number counting and pore radius and area measurement. For this purpose, the pore section was considered circular.

Other authors have estimated total pore area $(A p)$ in amniote eggshells by using varied indirect methods. For recent eggs, Ap is estimated by applying Fick's law to gas conductance values $G_{\mathrm{H} 2 \mathrm{O}}$ (directly measured in living eggs), using eggshell thickness (Ls) as a proxy for pore canal length (Ar and Rahn, 1985).

$A p=0.447 * G_{\mathrm{H} 2 \mathrm{O}} * L s$

An alternative method-which turns out to be more appropriated for fossil eggshells-obtains Ap by estimating total pore number $(N)$ through extrapolation of pore density $(D)$ in a shell fragment to total egg area (As) (Deeming, 2006). Individual pore area $(A)$ is averaged from measures in shell fragments:

$N=D^{*} A s$

then

$A p=N * A$

According to Paganelli et al. (1974), total eggshell area (As) for bird eggs scales to egg mass is as follows:

As $=4.835 * M^{0.662}$
Estimation of gas conductance for extinct eggs can be approached by two different methods:

- using Eq. (4), which relates gas conductance to eggshell thickness $(L S)$, as a proxy for pore canal length, and total functional pore area (Ap) (Table 2; Ar and Rahn, 1985; Deeming, 2006);

- applying the transfer function of regression between measured water vapor conductance against egg mass for bird eggs:

$G_{\mathrm{H} 2 \mathrm{O}}=A p /(0.477 * L s)$

In our work we adopt the criteria proposed by Deeming (2006), using maximum shell thickness including ornamentation, which slightly underestimates $G_{\mathrm{H} 2 \mathrm{O}}$ values, assuming that the pore section area is the same along the canal (Toien et al., 1987).

$G_{\mathrm{H} 2 \mathrm{O}}=0.384 * M^{0.814}$

\section{Results}

\subsection{Ornitholithus eggshells}

The rich Claret-4 sample of Ornitholithus eggshell fragments range from 1 to $10 \mathrm{~cm}^{2}$ average surface and about $1-3 \mathrm{~mm}$ thickness, most of them with their outer faces decorated with tubercles and furrows of different patterns and geometry (López-Martínez, 2000). The most remarkable external features of Ornitholithus from Claret- 4 are the important eggshell thickness and the conspicuous outer shell ornamentation (Figs. 3 and 4). Ornamentation varies from rugged external surface to irregular and heavy ridges and nodes (linearituberculate to ramotuberculate in Mikhailov's nomenclature). Ornamentation average height reaches $0.39 \mathrm{~mm}$.

Eggshell thickness (Ls) in our sample varies from 1.94 to $2.39 \mathrm{~mm}$ (average $2.17 \mathrm{~mm} ; n=6$ ) (Table 4), while it varies from 1.65 to $3.1 \mathrm{~mm}$ (average, $2.37 \mathrm{~mm} ; n=15$ ) in the sample measured by Kälin (1997) and from 2.1 to $2.9 \mathrm{~mm}$ (average, $2.38 \mathrm{~mm}$ ) in that measured by Dughi 


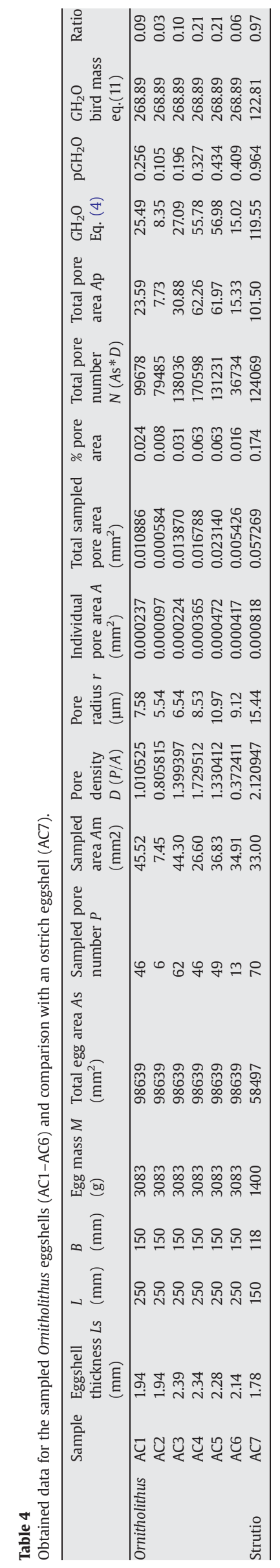

and Sirugue (1962). Several eggshell-thickness measurements can be made on the same eggshell fragment and variability in this feature scales with the importance of ornamentation in the outer shell surface, which varies from 0.32 to $0.54 \mathrm{~mm}$ (average $0.39 \mathrm{~mm} ; n=6$ ).

Up to 10 different eggshell types have been identified in the Claret-4 assemblage (Kälin, 1997), some of them matching the ootaxa described by Dughi and Sirugue (1962) as different Ornitholitus oospecies from Late Paleocene deposits in the Provence basin. At least six microstructural eggshell types named $A$ to $F$, all of them belonging to the ornithoid basic type, can be distinguished by eggshell shape and density of eggshell units, which can be parallel or fan-shaped and narrowly or widely packed, and by the ratio between mamillary and prismatic zones, which show a rather smooth transition between them. As an example of the eggshell microstructural diversity found in the Claret-4 sample, two types are shown in Fig. 3 (types A and F). Sampled eggshells studied here can be roughly assigned to the $A, C, D$ and $F$ types. Differences in porosity between different eggshell fragments do not seem to be related to morphotype differences. In this work, we have not considered the question of taxonomic diversity within the Ornitholithus genus, which would need a detailed study of the eggshell structural variability observed in extinct and extant archosaurs.

The Ornitholitus eggshell structure perfectly agrees with the diagnostic features of the Cretaceous Elongatoolithidae oofamily, such as the diffuse boundary between the mamillary and prismatic layers and the high ratio between their respective thicknesses (Dughi and Sirugue, 1962; Kälin, 1997; Carpenter, 1999; López-Martínez, 2000). The ornamentation type also agrees with this oofamily. This eggshell type is recorded in the Late Cretaceous of Mongolia and China (Mikhailov et al., 1994; Zhao, 1975, 1994, pers. com. 1999). The oviraptorid Citipati is associated with this eggshell type (GrelletTinner et al., 2006). Dughi and Sirugue (1962) already noted the surprising finding of presumably Paleocene birds having an eggshell similar to the oviraptoroid Cretaceous dinosaurs (see below).

\subsection{Egg mass estimation}

Most reproductive variables studied by authors on the Amniote egg are referred to egg mass. Egg mass estimations obtained for Ornitholithus eggs are summarized in Table 3 and Fig. 5.

All available data indicate that Ornitholithus eggs would have ellipsoidal or ovoid shape. According to Touraine (1960), the Ornitholithus egg section measures $L=240 \mathrm{~mm}$ and $B=150 \mathrm{~mm}$; on the other hand, Dughi and Sirugue (1962) obtained that $L=400 \mathrm{~mm}$ and $B=200 \mathrm{~mm}$ for the Ornitholithus arquatus oospecies group. The collector J. P. Villa (2006) showed rather complete Ornitholithus arquatus eggs from

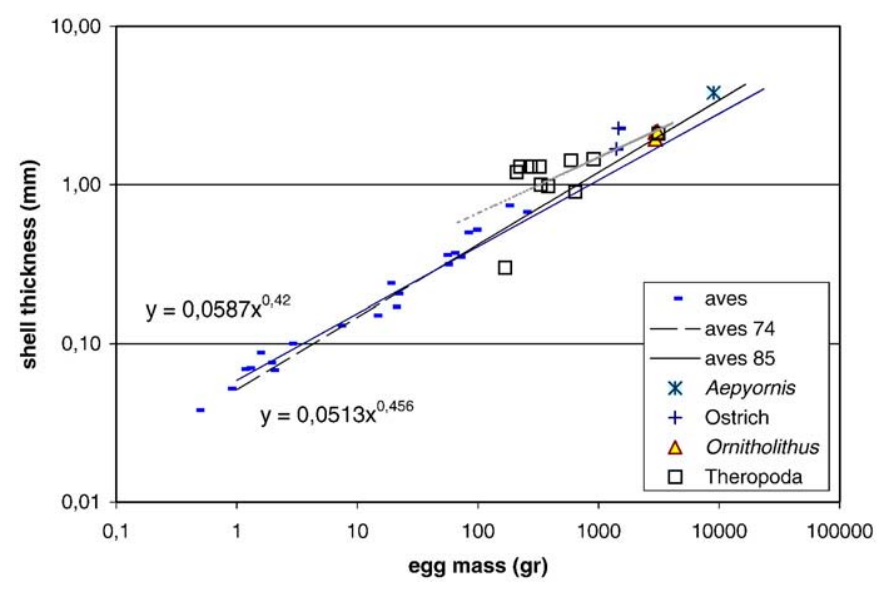

Fig. 5. Scatter plot between egg mass $(M)$ and eggshell thickness (Ls); two alternative regressions for recent bird data are shown (Aves '74 from Ar et al., 1974; Aves `85 from Ar and Rahn, 1985). Theropod data and regression taken from Deeming (2006). 
the Aix-en-Provence region, measuring $250 \times 150 \mathrm{~mm}$. In comparison, a recent ostrich egg measured by us gives $L=150 \mathrm{~mm}$ and $B=118 \mathrm{~mm}$.

According to these data, the size and shape of Ornitholithus eggs would correspond to a spheroid with $1023 \mathrm{~cm}^{2}$ of total surface (As) and $2945 \mathrm{~cm}^{3}$ of volume. The internal volume, discarding shell volume (for a $2.17 \mathrm{~mm}$ average eggshell thickness) would represent a weight of $2835.8 \mathrm{~g}$, which provides a weight of $3082 \mathrm{~g}$ for $1.087 \mathrm{~g} / \mathrm{cm}^{3} \mathrm{egg}$ density. Alternative estimations can be made by applying Eq. (1) to the Touraine and Villa measurements, thus obtaining a mass of $M=2959$ $3083 \mathrm{~g}$ for Ornitholithus eggs. We retain this last value for future calculations (see Table 4). In contrast, data from Dughi and Sirugue (1962) provide an unrealistic Ornitholithus egg mass of $8768 \mathrm{~g}$, around the mass of the largest egg ever reported (elephant bird Aepyornis).

\subsection{Pore canal system}

Pore number, pore radius and pore area measurements have been taken in Ornitholithus (total pore sampled, $n=222$ ) and ostrich Struthio $(n=70)$. Our observations show that both eggshell types strongly differ in the shape of their pore canal system, mostly straight and simple in ostrich, and complex, branching outwards in Ornitholithus, as well as in pore size and pore density (D) (Figs. 6-9, Table 4). The branching macropores in Ornitholithus split in a number of secondary pore canals of less entity when approaching the external surface. Connections between primary and secondary pore canals appear in radial sections as an elliptical pore section (Fig. 8). The collective aperture of the pore branching system occurs in elongated, narrow and deep furrows in outer eggshell surface (Figs. 6 and 7). These furrows appear in the external eggshell surface as simple or branching divergent fissures situated into depressed valleys between ornamental crests. The fissures reach about $1 \mathrm{~mm}$ deep, similar to that reported by Touraine (1960: Fig. 11a).

Large pores (macropores, average radius about $r=30 \mu \mathrm{m}$ ) are present in all ratite bird eggs; however, Ornitholithus eggshells additionally show a large number of very small pores (micropores, average radius about $r=7 \mu \mathrm{m}$ ), close to the size of the largest vesicles. Blind micropore canals seem to be tiny tubular vertical holes with circular section, lacking lateral and radial continuity and devoid of connections (Fig. 6a). This high microporosity characterizes Ornitholithus fossil eggshells (Figs. 8 and 9). Vesicles are also very frequent in Ornitholithus (approximately 70 vesicles were present on a single photo in AC1 sample).

\subsection{Measured porosity parameters}

\subsubsection{Pore number and density}

Pore density D (i.e., number of pores observed in an eggshell fragment per unit of area) is lower in Ornitholithus than in recent ostrich.

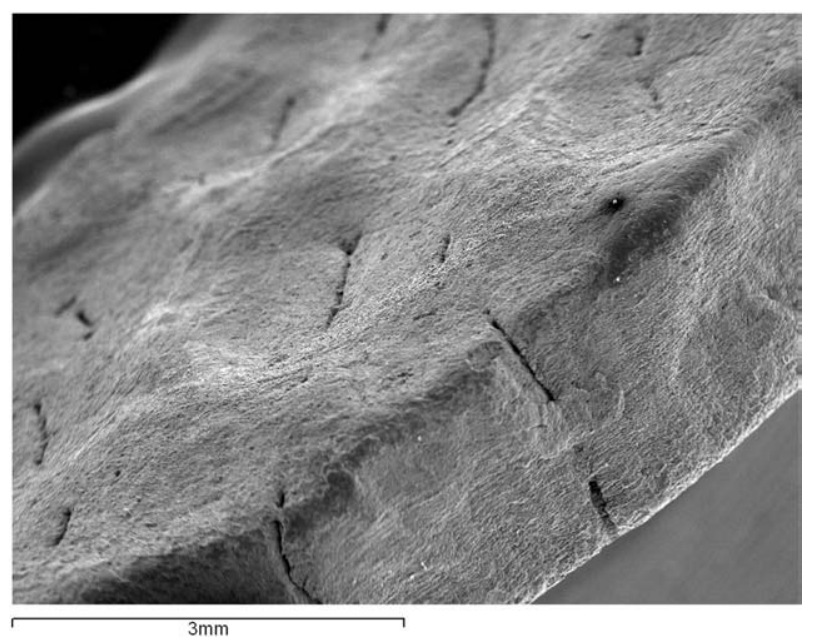

Fig. 7. SEM image showing the pore canal system in Ornitholithus eggshell, grouped together in deep fissures on the valleys between the tubercle ornamentation.

The number of pores per unit of area in our Ornitholithus samples varies from $D=0.37-1.73$ pores $/ \mathrm{mm}^{2}$ (average, $D=1.11$ pores $/ \mathrm{mm}^{2}$ ), against $D=2.12$ pores $/ \mathrm{mm}^{2}$ average in our ostrich eggshell. $D$ value for Ornitholithus includes micropores which are not recorded in recent ostrich eggs. Thus, pore density in Ornitholithus-as small as it might be-has been even highly overestimated here in relation to usual counting methods used by other authors (e.g., Williams et al., 1984; Jackson et al., 2008).

Comparison of pore density data between extinct and recent eggs is not straightforward, because of the use of different counting methods. Averaged $D$ values provided by Ar and Rahn (1985) for 161 recent birds range from $D=0.28-2.74$ pores $/ \mathrm{mm}^{2}$. Thus, pore number and pore density in Ornitholithus eggshells lie within the observed values for recent birds. Theropod dinosaur eggshells have much lower pore density than birds of comparable egg mass $(D=0.44$ pores/ $\mathrm{mm}^{2}$, ranging from 0.99 to $\left.0.18, \mathrm{SD}=0.245, n=11\right)$. Since only macropores had been counted by previous authors, Ornitholithus' pore density values may thus lay close to theropod $D$ values.

Pore number per unit of area is allometrically related to egg mass. A regression function links the number of pores per unit area $(D)$ with egg mass $(M)$ in recent birds, as calculated by previous authors (Eq. (2): $D=0.629 * M^{0.105}$; Deeming, 2006; data from Ar and Rahn, 1985). According to this function, the expected value for ostrich is $D=1.35$ pores $/ \mathrm{mm}^{2}$ (lower than observed) and $D=1.46$ pores/ $\mathrm{mm}^{2}$ (higher than observed) for Ornitholithus.

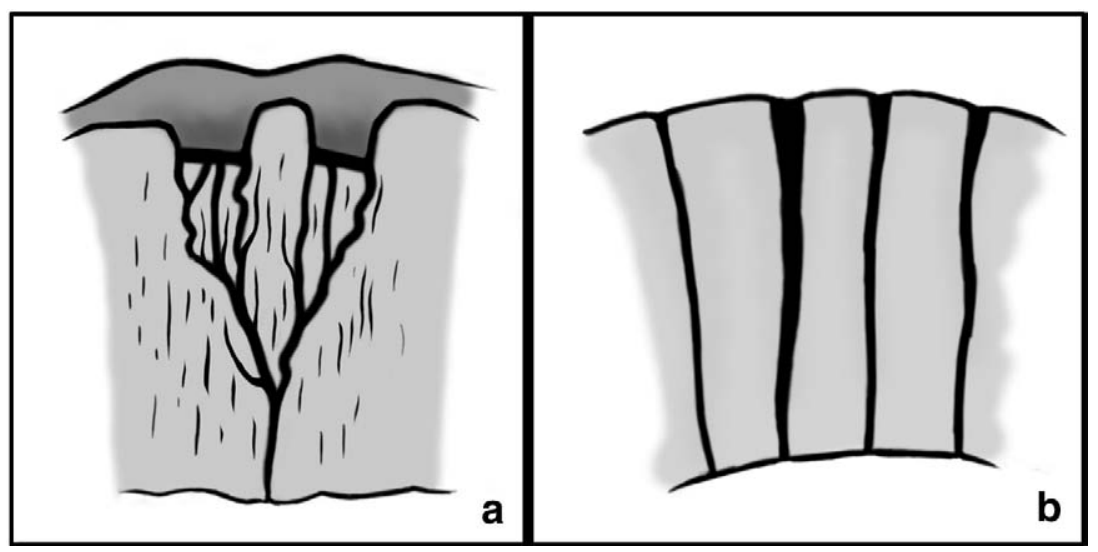

Fig. 6. Scheme of the radial section with the pore canal system for Ornitholithus (a) and ostrich (b). 


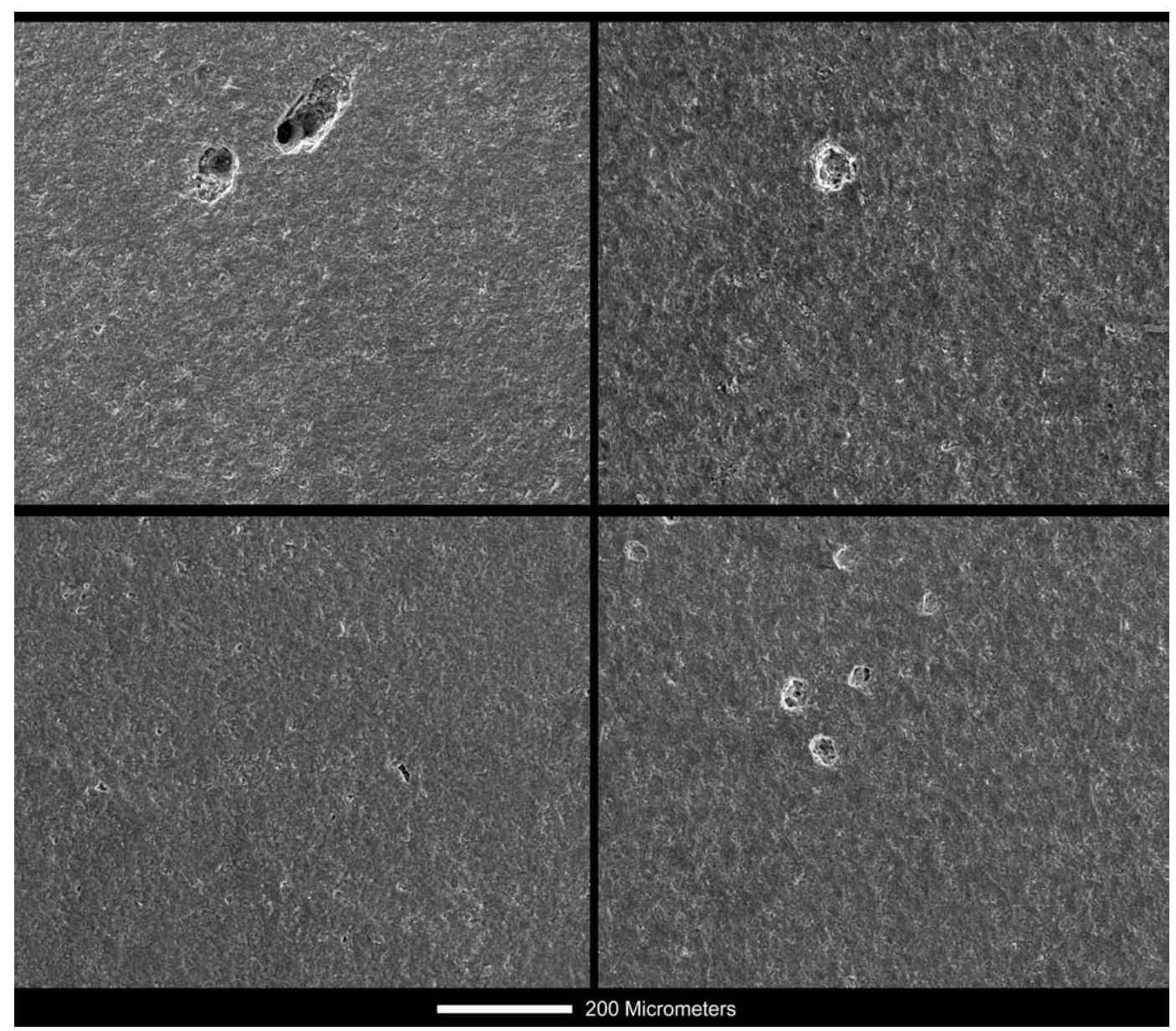

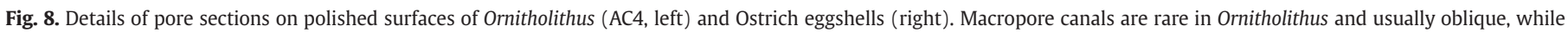
eggshells macropore canals are frequent and straight in ostrich. Micropores are only frequent in Ornitholithus.

\subsubsection{Pore size}

Individual pore size ( $r$ and $A$ ) has been measured for all counted pores. Measured pore size values show relatively low variability between different specimens of Ornitholithus eggshells. Average pore radius in Ornitholithus measures $r=8.05 \mu \mathrm{m}(n=222, \mathrm{SD}=5.10)$, while it is twice as much $(r=15.44 \mu \mathrm{m}, n=70, \mathrm{SD}=4.73)$ in ostrich (see Table 4).

The frequency distribution of pore radius clearly shows the existence of different proportion of large and small pore sizes between

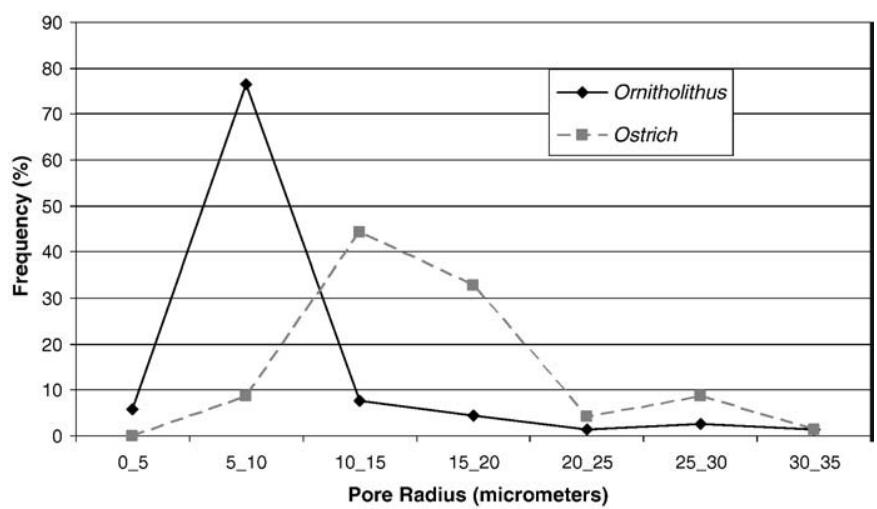

Fig. 9. Frequency distribution of pore radius from Ornitholithus (continuous line) compared to that from ostrich (doted line).
Ornitholithus and ostrich eggshells (Fig. 9). Most pores in Ornitholithus eggshell (76.6\%) have pore-radio values ranging within the 5-10 $\mu \mathrm{m}$ interval (micropores), whereas in the recent ostrich the highest frequency $(77.2 \%$ ) is reported within the $10-20 \mu \mathrm{m}$ interval (macropores; Fig. 9, Table 4). The T-Student test indicates that this difference is highly significant. As we have already seen, eggshell porosity is mainly constituted by macropores in ostrich, while Ornitholithus porosity is mainly constituted by micropores (Figs. 8 and 9). Similarly, individual pore area is lower in Ornitholithus $\left(A=0.000318 \mathrm{~mm}^{2}\right.$ average; range $\left.0.003078-0.000074 \mathrm{~mm}^{2}\right)$ than in ostrich $(A=$ $0.000818 \mathrm{~mm}^{2}$; range $0.003182-0.000101 \mathrm{~mm}^{2}$ ). Ornitholithus eggshells have $0.03 \%$ average pore area (range $0.06-0.008 \%$ ) against $0.17 \%$ in ostrich. These values clearly indicate much lover porosity (including micropore porosity) in Ornitholithus than in ostrich eggshells.

Individual pore radius $(r)$ is in birds $3.177 * M^{0.230}$ (Eq. 3, Deeming, 2006). The low allometric coefficient indicates that pore radius is nearly independent of egg mass.

\subsubsection{Total pore area}

Estimation of total pore area for Ornitholithus eggs by using Eqs. (5), (6) and (7)) provides a total average pore-area $A p=$ $33.63 \mathrm{~mm}^{2}$ (range $62.26-7.73 \mathrm{~mm}^{2}, \mathrm{SD}=22.77$ ), a total pore number $N=109293$ (170578-79485) and total egg surface $A s=986.39 \mathrm{~cm}^{2}$ (slightly lower than the theoretical estimation $A s=1023 \mathrm{~cm}^{2}$ ). Using the same method for an ostrich egg, we obtain $A \mathrm{p}=101.5 \mathrm{~mm}^{2}$ for $N=124069$ and $A s=585 \mathrm{~cm}^{2}$ (see Table 4). 
We can also estimate the expected Ap value for recent bird eggs of known egg mass. According to Ar and Rahn (1985), total pore area Ap scales with egg mass in bird eggs as:

$A p=0.0098 * M^{1.236}$

This function predicts a total pore area $A \mathrm{p}=194.5 \mathrm{~mm}^{2}$ for a bird egg of about $3 \mathrm{~kg}$ weight, the estimated egg mass for Ornitholithus. This expected $A \mathrm{p}$ value strongly contrasts with the estimated Ap value for Ornitholithus eggs ( $\mathrm{pp}=33.63 \mathrm{~mm}^{2}$, around 6 times lower). For recent ostrich eggs, the difference between expected $(A \mathrm{p}=$ $\left.82.57 \mathrm{~mm}^{2}\right)$ and estimated values $\left(A \mathrm{p}=101.5 \mathrm{~mm}^{2}\right.$ from our data; $A p=175 \mathrm{~mm}^{2}$ from Fig. 1 in Rahn et al., 1979:45) is relatively smaller and its residual bears the opposite sign (estimated values exceed 11/2 times the expected value; Fig. 10).

Theropods' scaling trend is similar to that of birds, as well as similar pore density (Deeming, 2006; Eq. 10, Fig. 10), but they have about 5 times more porous eggshells, due to their larger averaged individual pore area. According to these data, Deeming (2006) concluded that theropod dinosaur nests were necessarily buried in a substrate (covered by sand or vegetation) and could not be incubated in open nests by direct contact with the adult bodies (contra Norell et al., 1995, and Horner, 2000, among others).

\subsection{Conductance}

In recent ostrich eggshells, conductance estimations provide similar results by using Eqs. (4) or (11) (119.6 and $122.8 \mathrm{mg} \mathrm{H} \mathrm{H}_{2} \mathrm{O}$ / day*Torr, respectively; Table 4); both values are close to the actual measured value (104.76 mg $\mathrm{H}_{2} \mathrm{O}$ /day*Torr; Ar et al., 1974), which provides high reliance to these procedures.

However, in the case of Ornitholithus eggshells, conductance values obtained by using these equations provide different results. The value obtained for Ornitholithus gas conductance by using Eq. (4) (based on the total pore area and pore length) averages $G_{\mathrm{H} 2 \mathrm{O}}=31.45 \mathrm{mg} \mathrm{H}_{2} \mathrm{O}$ / day*Torr (range 8.35-56.98 $\mathrm{mg} \mathrm{H}_{2} \mathrm{O}$ /day*Torr). In contrast, a much higher value for Ornitholithus gas conductance is obtained by using Eq. (11) (based on conductance regression against egg mass for modern bird eggs; $G_{\mathrm{H} 2 \mathrm{O}}=268.89 \mathrm{mg} \mathrm{H}_{2} \mathrm{O}$ /day*Torr; see Table 4). This is the predicted value for gas conductance in a modern bird egg of around $3 \mathrm{~kg}$ of egg mass, which corresponds to the respiratory needs of recent bird eggs lying in open air nests.

Gas-conductance values obtained for Ornitholithus from measured porosity values is thus 8 times lower in average (ranging 5-32 times) than those obtained for recent birds eggshells of similar egg mass (Table

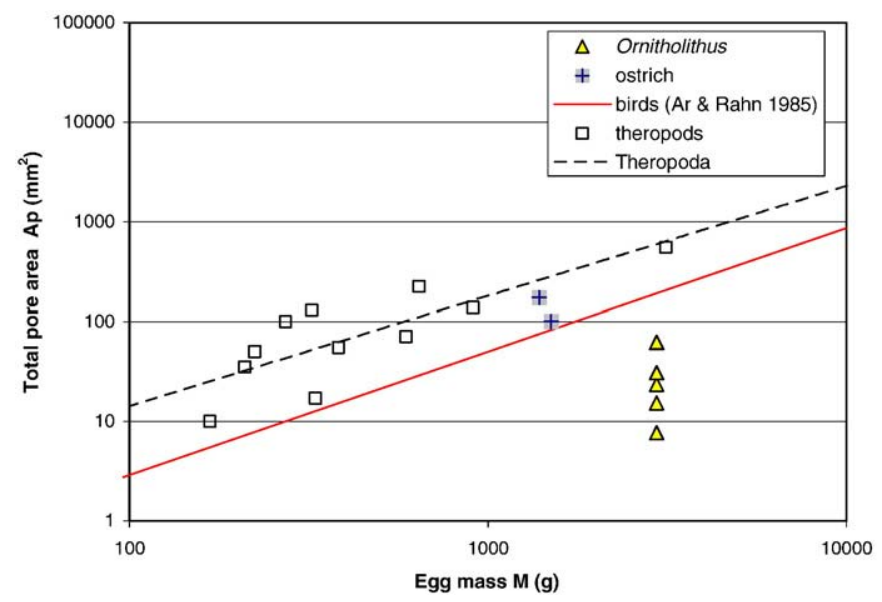

Fig. 10. Scatter plot of total pore area $(A p)$ against egg mass $(M)$. Theropods in general have much more porosity than birds of similar egg mass (data form Deeming, 2006). Ornitholithus eggshells have extremely low porosity ( 6 times less than expected for a bird of similar egg mass).
4). As we have already seen, low conductance values in Ornitholithus are a consequence of the low porosity (low $r, A$ and $A \mathrm{p}$ ) observed in Ornitholithus eggshells in relation to modern bird eggshells.

The conductance value per pore in Ornitholithus (Eq. 12, $G_{\mathrm{H} 2 \mathrm{O}}=$ $0.288 \mathrm{mg} \mathrm{H}_{2} \mathrm{O}$ /day*Torr average) is also much lower than that of recent bird eggs of the same mass ( $\mathrm{pG}_{\mathrm{H} 2 \mathrm{O}}$ about $1.19 \mathrm{mg} \mathrm{H}_{2} \mathrm{O}$ / day*Torr, Eq. 13), due to small average pore radius. This variable seems little affected by egg mass, as pointed out by Ar and Rahn (1985): Regression for bird eggs $\mathrm{pG}_{\mathrm{H} 2 \mathrm{O}}=1.190 * \mathrm{M}^{0.050}$ shows nearly constant gas conductance per pore. Thus, the studied Ornitholithus eggshells are unique in their extremely low gas conductance per pore (24\% of the extraordinarily constant $\mathrm{pG}_{\mathrm{H} 2 \mathrm{O}}$ value for birds). This variable is of great interest for physiological inferences on fossil eggs, due to its independence from egg mass (see below).

\section{Discussion}

\subsection{Eggshell type and egg-laying taxon}

Ornitholithus eggshells belong to a structural type which is similar to that of ratite birds; this eggshell type is not characterized by common derived features (synapomorphies) and thus cannot be used to assign these eggs to any known avian or non avian theropod taxon (Zelenitsky and Modesto, 2003).

As we have shown the Ornitholithus eggshell structure clearly belong to the Elongatoolithidae oofamily (see above; Dughi and Sirugue, 1962; Kälin, 1997; Zhao, 1975, 1994, pers. com. 1999; Carpenter, 1999; López-Martínez, 2000). The Elongatoolithidae oofamily is one of the most extended ootaxa in the Upper Cretaceous of Mongolia and China (Zhao, 1975, 1994; Mikhailov et al., 1994), but not exclusively since a similar egg type has also been found in Upper Cretaceous deposits at the Northern Pyrenees (Beetschen et al., 1977). The chronology of this oofamily spans thus from Late Cretaceous to Late Paleocene, crossing the Cretaceous-Tertiary boundary.

Eggs having this eggshell type have been found associated to an adult brooding oviraptorid dinosaur (Grellet-Tinner et al., 2006), and the oofamily is commonly attributed to non-avian theropod dinosaurs (Carpenter, 1999). Instead, Ornitholitus eggshells have been attributed to birds because of their late Paleocene age, although they have not been found related to avian bones yet. Some of the Cretaceous eggshells from this oofamily could also be laid by birds, since there are records of giant birds in the Cretaceous of the Pyrenees (Buffetaut and Leloeuff, 1998), although not associated with eggshells.

A close relationship between birds and non-avian theropod dinosaurs has been noted in the eggshell structure (Zelenitsky and Modesto, 2003) which supports the idea that some taxa from both groups could share a similar eggshell structure, like that assigned to the Elongatoolithidae oofamily. In fact the phylogeny based on bone morphology includes the oviraptoroid dinosaurs within the avian clade (Maryańska et al., 2002).

The particular birds that could lay Ornitholithus eggshells cannot be identified yet. Buffetaut (2002) summarized the findings of giant fossil birds from the Late Cretaceous to Lower Eocene in Europe, but these findings are bones not associated with eggshells. In Late Paleocene and Lower Eocene deposits in Northern Europe, the only large birds-whose size could fit with Ornitholithus eggs-are the Gastornithidae family, more frequent in the Early Eocene; however, Gastornithidae are not good candidates, since they seem to be related to Gruiform or Galloanserae and not to ratite birds (Mayr, 2007). Moreover, their distribution does not overlap with that of Ornitholithus, which seems to be limited to south-western Europe. A single bone attributed to a giant bird (Gargantuavis, Buffetaut and Leloeuff, 1998) from Upper Cretaceous deposits in southern France does not allow being conclusive about its affinities.

External eggshell features and eggshell microstructure allowed Kälin (1997) to recognise different morphotypes in the rich eggshell 
sample from Claret-4. The existing great variability within this oogenus was already recognized in previous works, although differences in external eggshell features do not necessarily mean taxonomic differences of the egg-laying species, since a single avian species can show important variability in these features. Conversely, similar external features may hide important structural and taxonomic differences. Thus, for taxonomic distinction of eggshell types, internal microstructural features such as size and density of eggshell units and mamillary cores must be considered.

Dughi and Sirugue (1962) distinguished five different Ornitholithus oospecies in the Provence sample, which can be compared to eggshell types from Claret-4. Features such as eggshell thickness and eggshell-unit shape and size seem to match Claret type A with $O$. arquatus and type $\mathrm{F}$ with $\mathrm{O}$. mammosus oospecies. A smaller oospecies, Ornitholithus biroi, was described by Dughi and Sirugue (1962) in a lower level in Provence deposits, which had not been recorded in the Tremp Fm yet. It has smooth and thinner eggshells and is absent in the uppermost Paleocene levels, according to these authors. In conclusion, the Ornitholithus oogenus was represented by several oospecies in the Late Paleocene in southwest Europe.

The eggshell structure of recent bird eggs is more distant from Ornitholithus than that of Ornitholithus is from theropods. The oofamily Elongatoolithidae in particular -and most theropods in general- have thicker eggshells than recent birds in relation with their egg mass (calculated from fossil entire eggs). According to the compilation of Deeming (2006), regression between egg mass and eggshell thickness in theropods significantly differs from that of bird eggs (Fig. 5); a $1 \mathrm{~mm}$-thick eggshell would correspond to a bird egg weighting $0.855 \mathrm{~kg}$, but to a theropod egg weighting just $0.325 \mathrm{~kg}$. These differences are less important for large eggs; thus, Ornitholithus egg mass and eggshell thickness fit well with both regression functions for birds and larger theropod eggs (Fig. 5).

\subsection{Porosity, conductance and environment}

Ornitholithus eggshell seems unique in having a high number of closed micropore canals situated between its main pore canals (Fig. 6a). Blind pores have not been reported in bird eggs, to our knowledge; previous authors studying pore number and gas conductance in dinosaurs and birds do not distinguish between blind or functional pore canals, which can hardly be detected with usual observation methods. Only in the sauropod dinosaur oospecies $\mathrm{Me}$ galoolithus siruguei, blind macropores have been signaled after 3D reconstruction (Elez and López-Martínez, 2000). Further studies are necessary to detect the existence of non-functional, blind pores in eggshells. The function of closed pores in eggshells is necessarily different from the respiratory function (see below).

The observed shape and connectivity of macropore canals strongly differs between Ornitholithus and ostrich eggs. The macropore canal system of Ornitholithus eggshells reconstructed here (Fig. 6)-with secondary branching canals opening in deep fissures-is similar to those of modern South-American Rhea ("ñandu") and differs from most pore systems described in recent birds (Rahn et al., 1979; Toien et al., 1987; Mikhailov, 1997). These fissures are likely to produce a funnel effect which improves gas conductance throughout the eggshell (Toien et al., 1987).

In contrast, the pore canal system of our ostrich eggshell samples seems to be simple and straight, without branching. Pore canals simply become slightly larger when opening in a slight depression on the external surface (Figs. 6 and 8). We have not found in our study on ostrich eggshells the peculiar, highly ramified pore system figured by Rahn et al. (1979) and Tullet (1984) according to previous studies by Tyler et al. (see Toien et al., 1987) and also referred to by Zelenitsky and Modesto (2003). Instead, we have predominantly observed simple, straight pore canals in Struthio, although a high variability exists in the egg pore system of a single species. Additional ostrich egg samples have been studied through computer microtomography by Páramo (2008), who recognizes mostly simple pore canals among the numerous sampled macropores.

Functional total pore area in eggs-directly linked to gas conductance-is the critical value for egg physiology, respiration and water loss of the developing embryo (Ar et al., 1974; Ar and Rahn, 1985). The functional pore area of fossil eggshells cannot be directly measured since both functional and blind porosity are measured together; thus observed porosity in fossil eggshells overestimates its real functional porosity. Even so, total pore area $(A p)$ of Ornitholithus egg is very low: about 6 times lower than that of a bird with similar egg mass (Fig. 10). Since most Ornitholithus pores are exceedingly small, Ornitholithus egg, consequently, has a very low effective total pore area in relation to birds and theropod dinosaurs. The low connectivity of the numerous blind, totally closed micropores in Ornitholithus indicates that these anomalous compact eggshells were extremely impermeable. In conclusion, Ornitholithus eggshells are the most compact of all studied bird or theropod eggshells.

Pore size, pore number and pore density have been measured by previous authors in a large number of egg types and been have found to vary strongly across taxa in a predictable way (Ar et al., 1974). In subterranean nests, buried eggs have many more pores than those in open air. Gas conductance of eggshells is directly related to nest environment and, thus, it provides an important proxy data for estimating palaeoclimatic conditions in past environments of fossil eggs (Horner, 2000; Deeming, 2006). Ar and Rahn (1985) studied the ratio (o/p) between observed (o) and predicted (p) $\mathrm{G}_{\mathrm{H} 2 \mathrm{O}}$ values in recent bird eggs, linked to relatively more arid or humid nest environments. A ratio $o / p=1$ would correspond to the ideal conductance model for bird eggs, allometrically scaled to egg mass. Ratios higher than 1 (ratio $o / p \approx 2-3$ ) are found in wet nest environments (grebes, loons, brush turkey, etc.) where transpiration is higher, while ratios below $1(0 / p \approx 0.3-0.4)$ are found in dry nest environments in arid landscapes (sand partridge, sandgrouse, etc.), where more compact eggshells protect developing embryos against excessive water loss.

According to the foregoing, the value for ostrich $o / p G_{\mathrm{H} 2 \mathrm{O}}$ ratio $(o / p=0.79-0.85)$ indicates its preference for open nests in semiarid climates, since nesting environment temperature and humidity are climate-controlled (Deeming, 2006). Ostrich eggs show higher-thanpredicted Ap values (larger porosity area) but higher-than-predicted eggshell thickness (longer pore canals), resulting in a lower than predicted gas conductance.

In the case of Ornitholithus, the much lower-than-predicted Ap values led to exceedingly low gas conductance. The $o / p G_{\mathrm{H} 2 \mathrm{O}}$ ratio in Ornitholithus ranges from 0.2 to 0.02 (average 0.1 ), as obtained by dividing conductance values based on porosity (obtained $G_{\mathrm{H} 2 \mathrm{O}}$ value: 57 max., 8.36 min., 31.45 average $\mathrm{mg} \mathrm{H}_{2} \mathrm{O}$ /day*Torr) between that based on regression for recent bird eggs (predicted $G_{\mathrm{H} 2 \mathrm{O}}$ value: $268.89 \mathrm{mg} \mathrm{H}_{2} \mathrm{O}$ / day*Torr, corresponding to a large bird egg similar to Ornitholithus). These small ratios in $\mathrm{o} / \mathrm{p}$ conductance values for Ornitholithus are lower than in any other studied bird eggs. These indicate extremely dry nest environments for Ornitholithus and-by extension-an extremely arid palaeoclimate for latest Paleocene times in the Pyrenean-Provence region.

Conductance values calculated for theropod dinosaur eggs by Deeming (2006)-most of them from Cretaceous eggs belonging to the Elongatoolithidae oofamily-are 2-7 times larger than those for bird eggs, except a single case of a theropod dinosaur egg which agrees with the predicted conductance for bird eggs $(o / p$ ratio $=0.9)$. Thus, Cretaceous Elongatoolithidae show much higher conductance than Late Paleocene Elongatoolithidae Ornitholithus, which has the lowest conductance value reported in eggshells, indicating that conductance has stronger dependence on nest environment than on phylogenetic relatives.

Despite of the normal pore number and pore density in Ornitholithus eggshell, its gas conductance values are much lower than those 
for bird and theropod-dinosaur eggs with similar egg mass, due to its much smaller pores. This low conductance implies that Late Paleocene eggs were laid in open nest environments with extremely dry climate, where a compact eggshell would be favorable to maintain egg internal humidity. Extremely compact Ornitholithus eggshells reach 6 times less total pore area and 5-32 less gas conductance than bird eggs of the same size. According to the relation between nest environment and gas conductance observed in recent eggs, a clear conclusion can be drawn from the extreme adaptation of Ornitholithus eggs to arid environments. In contrast, Cretaceous eggshells of the same Elongatoolithidae oofamily show around 50 times higher conductance, indicating a more humid nest environment.

The important microporosity of Ornitholithus seems not related with conductance, because its lack of connectivity. Thermal protection may be one of the functions of the microporosity, which-to our knowledge-has not been signaled in other eggshells. Abundant, isolated micropores are likely to have provided the embryo with protection against warm environments working as insulating chambers against overheating. Micropores could also favour easier hatching, facilitating the break-up of the thick eggshell by hatchlings.

The rapid appearance, spread and extinction of the Ornitholithus eggshells in the latest Paleocene in the Pyrenean-Provence region, as well as their anomalous eggshell structure, seems clearly linked to the Paleocene-Eocene Thermal Maximum (PETM), which is detected in the region by the CIE geochemical anomaly just above the Ornitholithus-bearing levels. This abrupt climatic global warming produced important environmental changes which could favor the spread of highly specialized vertebrates such as the Paschatherium acme, also reported in Claret-4 (López-Martínez et al., 2006).

Warm climate conditions during PETM are known to have produced an arid climatic belt in the Pyrenean-Provence region, as demonstrated by the spread of gypsum deposits in the otherwise lutitic coastal deposits. The extremely dry climate inferred for the Ornitholithus nesting palaeoenvironment slightly predates the widespread Claret conglomerate, which overlies the fossil-bearing Claret- 4 level and has been interpreted as a giant megafan produced by extreme torrential, seasonal rains (Schmitz and Pujalte, 2007). According to these authors, the PETM onset coincides with the Claret conglomerate, after the deposit of the Claret- 4 fossil assemblages. Further geochemical studies will help us obtain a more detailed and accurate calibration of the palaeoclimatic changes which took place at the beginning of the PETM in the Pyrenean region.

\section{Conclusions}

The study of Ornitholithus eggshells fragments from Upper Paleocene in the Claret- 4 site (south-central Pyrenees) has allowed observation of the geometry of its pore system and come to conclusions about eggshell permeability, which is closely linked to nesting environment. This oogenus-belonging to the theropod Elongatoolithidae oofamily-has been attributed to giant birds, which spread for a short period in the Pyrenean-Provence region at the beginning of the global warming event known as the PaleoceneEocene Thermal Maximum (PETM).

The eggshell fragments studied confirm the existence of a large variability within this oogenus. Almost 10 eggshell types can be distinguished in the Claret- 4 assemblage, according to the work by Kälin (1997).

The estimation of Ornitholithus egg mass-which conditions all allometric relations-suggests an egg mass of about $3 \mathrm{~kg}$, close to the measurements obtained by Touraine (1960). In relation to egg mass, Ornitholithus had very thick and heavily ornamented eggshells, with ramified pore canals opening into deep furrows. Its physiological characteristics are linked to eggshell porosity, which is exceedingly small in relation to birds. Ornitholithus total pore numbers are similar to birds and theropod dinosaurs, but most of them are micropores with very small radii and there is low connectivity between them. The values obtained for gas conductance are extremely low: about 5-32 times lower than those of bird eggs and much lower than those of non-avian theropod dinosaur eggs. The function of the numerous, blind micropores observed in Ornitholithus could be both thermal isolation and favoring hatchlings by lightening the thick, heavy and compact eggshell.

The low gas conductance values estimated for Ornitholithus are indicative of an open nest environment conditioned by an extremely dry and warm climate. The peculiar adaptation of these eggs suggests that these birds lived in an extreme climate related to the major global climatic change known as the Paleocene-Eocene Thermal Maximum (PETM). The onset of this event recorded by the CIE anomaly has been situated just above the Claret- 4 fossil site. A more accurate knowledge and understanding of the events around this major global palaeoclimatic crisis would require further detailed studies.

\section{Acknowledgments}

Thanks to Carlos Alonso Recio (photographer of the UCM Department of Palaeontology) for the high quality of his optical photos and for his rapid and kind disposition. Thanks to SEM operators of MNCN-CSIC, whose photos have provided the basis of the present work. Thanks to the operators from the UCM Microscopy centre for their photos, which allowed us to devise an adequate study method. We thank Otto Kälin for kindly providing unpublished data. Thanks to David Fernandez Remolar, a member of the CAB-INTA, for his help in obtaining SEM images. Thanks are due to Dr. Pedro Anadon (CSIC, Barcelona, Spain) and to the late Dr. Yvette Tambareau (CNRS, Toulouse, France) for kindly providing us with their invaluable field knowledge and access to samples. Thanks are also due to Jose Francisco Martínez de Andres for his help in reaching the CAB on time, to Roberto Cañadas Martín, Patricio Domínguez and Adrian Burton for their help with the English text, and to the journal's editor and anonymous reviewers for their comments for improving the first version of the manuscript.

\section{References}

Ar, A., Paganelli, C.V., Reeves, R.B., Greene, D.G., Rahn, H., 1974. The avian egg: water vapor conductance, shell thickness, and functional pore area. Condor 76, 153-158.

Ar, A., Rahn, H., 1985. Pore in avian eggshells: gas conductance, gas exchange and embryonic growth rate. Respir. Physiol. 61, 1-20.

Beetschen, J.C., Dughi, R., Sirugue, F., 1977. Sur la présence de coquilles d’oeufs d’Oiseaux dans le Crétacé supérieur des Corbières occidentales. C.R. Acad. Sci. Paris 284 2491-2494.

Board, R.G., Scott, V.D., 1980. Porosity of the avian eggshell. Am. Zool. 20, 339-349.

Buffetaut, E., 2002. Giant ground birds at the Cretaceous-Tertiary boundary: extinction or survival? Geol. Soc. Am., Spec. Pap. 356, 303-306.

Buffetaut, E., Leloeuff, J., 1998. A new giant ground bird from the Upper Cretaceous of southern France. J. Geol. Soc. Lond. 155, 1-4

Carpenter, K., 1999. Eggs, Nests, and Baby Dinosaurs. InIndiana University Press, p. 336

Deeming, D.C., 2006. Ultrastuctural and functional morphology of eggshells supports the idea that dinosaur eggs were incubated buried in a substrate. Palaeontology 49 171-185.

Díaz Molina, M., Kälin, O., Benito, M.I., López-Martínez, N., Vicens, E., 2007. The depositional setting of the dinosaur eggshell-bearing Aren Fm at Bastus (Late Cretaceous, south-central Pyrenees). Sediment. Geol. 199, 205-221.

Domingo, L., López-Martínez, N., Leng, M.J., Grimes, S.T., 2009. The Paleocene-Eocene Thermal Maximum record in the organic matter of the Claret and Tendruy continental sections (South central Pyrenees, Lleida, Spain). Earth Planet. Sci. Lett. 281, 226-237.

Dughi, R., Sirugue, F., 1962. Distribution verticale des oeufs d'oiseaux fósiles de l'Eocène de Basse-Provence. Bull. Soc. Geol. Fr. 7, 69-78.

Elez, J., López-Martínez, N., 2000. Interrelationships between growth of mineral phase and pore system in dinosaur eggshells. In: Bravo, A., Reyes, T. (Eds.), First International Symposium on Dinosaur eggs and babies. Extended abstracts. Publ Exma. Diputación Lleida, pp. 43-49.

García Veigas, F.J., 1988. La formacion evaporitica de la facies garumniense de la conca de Tremp (Lleida): Petrologia, Geoquimica y Sedimentologia. Public. Universidad Autónoma de Barcelona, Tesis de Lic., Bellaterra (Barcelona), pp. 175.

Grellet-Tinner, G., 2000. Phylogenetic interpretation of eggs and eggshells of Paleognathae. In: Bravo, A., Reyes, T. (Eds.), First Int. Symp. Dinosaur Eggs and Babies. Extended abstracts. Publ. Exma. Diputación Lleida, pp. 61-75. 
Grellet-Tinner, G., Chiappe, L., Norell, M., Bottjer, D., 2006. Dinosaur eggs and nesting behaviors: a paleobiological investigation. Palaeogeogr. Palaeoclimatol. Palaeoecol. 232, 294-321.

Horner, J.R., 2000. Dinosaur reproduction and parenting. Ann. Rev. Earth Planet. Sci. 28 , $19-45$.

Hoyt, D.F., 1987. Practical methods of estimating volume and fresh weight of bird eggs. Auk 96, 73-77.

Jackson, F.D., Varricchio, D.J., Jackson, R.A., Vila, B., Chiappe, L.M., 2008. Comparison of water vapor conductance in a titanosaur egg from the Upper Cretaceous of Argentina and a Megaloolithus siruguei egg from Spain. Paleobiology 34, 229-246.

Kälin, O., 1997. Structure of Late Paeocene Avian Eggshells. Unpublished Report Depto. Paleontología UCM, pp. 19

Kennett, J.P., Stott, L.D., 1991. Abrupt deep-sea warming, paleoceanographic changes and benthic extinctions at the end of the Paleocene. Nature 353, 225-229.

López-Martínez, N., 2000. Eggshell sites from the Cretaceous-Tertiary transition in south-central Pyrenees (Spain). In: Bravo, A., Reyes, T. (Eds.), First Int. Symp. Dinosaur eggs and babies. Extended abstracts. Publ. Exma. Diputación Lleida, pp. 95-115.

López-Martínez, N., Ardévol, L., Arribas, M.E., Canudo, J.I., Lacasa, A., Pereda-Suberbiola, X., Soler-Gijón, R., Torices, A., Vicens, E., 2002. The record of the dinosaur extinction in the south-central Pyrenees. In: Brock, G.A., Talent, J.A. (Eds.), First Internationa Paleontological Congress, Abstract book, p. 234.

López-Martínez, N., Moratalla, J.J., Sanz, J.L., 2000. Dinosaur nesting in tidal flats. Palaeogeogr. Palaeoclimat. Palaeoecol. 160, 153-163.

López-Martínez, N., Smith, R., Peláez-Campomanes, P., Smith, T., 2006. The acme of the micromammal Paschatherium acros the Paleocene-Eocene boundary in continental Europe. Micropaleontology 52 (3), 267-280.

Maryańska, T., Osmólska, H., Wolsan, M., 2002. Avialan status for Oviraptorosauria. Acta Palaeontol. Pol. 47 (1), 97-116.

Mayr, G., 2007. The birds from the Paleocene fissure filling of Walbeck (Germany) J. Vertebr. Paleontol. 27, 394-408.

Mikhailov, K.E., 1997. Avian eggshells: an atlas of scanning electron micrographs. British Ornithologists' Club. Occas Publ. 3, 88.

Mikhailov, K.E., Sabath, K., Kurzanov, S., 1994. Eggs and nests from the Cretaceous of Mongolia. In: Carpenter, K., Hirsch, K.F., Horner, J.R. (Eds.), Dinosaur eggs and babies. Cambridge University Press, pp. 88-115.

Mikhailov, K.E., Bray, E.S., Hirsch, K.F., 1996. Parataxonomy of fossil egg remains (Veterovata): basic principles and applications. J. Vertebr. Paleontol. 16 (4), 763-769.

Norell, M.A., Clark, J.M., Chiappe, L.M., Dashzeveg, D., 1995. A nesting dinosaur. Nature $378,774-776$
Paganelli, C.V., Olszowka, A., Ar, A., 1974. The avian egg: surface area, volume and density. Condor 76, 319-325.

Páramo, A., 2008. Estudio de la microestructura de las cáscaras de huevo de aves del Paleoceno de los Pirineos surcentrales. Master Thesis in Palaeontology, Univ. Complutense, pp. 38

Plaziat, J.C., 1984. Le domaine Pyrénnén de la fin du Crétacé à la fin de l'Éocène. Stratigraphie, paléoenvironnements et évolution paléogéographique. Thesis Univ. Paris-Sud, Orsay. vol. 2885, 1-1362.

Plaziat, J.C., Sirugue, F., Dughi, R., 1969. La répartition stratigraphique des oeufs d’ oiseaux du groupe d’Ornitholithus arcuatus D. \& S. par rapport aux faunes d'eau douce et marines du Sparnacien et du Thanétien de l’Aude. C. R. Som. séances de la Société géologique de France vol. 1, 9-10.

Rahn, H., Ar, A., Paganelli, C.V., 1979. How bird eggs breathe. Sci. Am. 240, 38-47.

Sanz, J.L., Moratalla, J., Diaz-Molina, M., López-Martínez, N., Kälin, O., Vianey-Liaud, M., 1995. Dinosaur nest at the sea shore. Nature 376, 731-732.

Schmitz, B., Pujalte, V., 2003. Sea-level, humidity, and land-erosion records across the initial Eocene thermal maximum from a continental-marine transect in northern Spain. Geology 31 (8), 689-692.

Schmitz, B., Pujalte, V., 2007. Abrupt increase in seasonal extreme precipitation at the Paleocene-Eocene boundary. Geology 35 (3), 215-218.

Seymour, R.S., 1979. Dinosaur eggs: gas conductance through the shell, water loss during incubation and clutch size. Paleobiology 5,1-11.

Toien, O., Paganelli, C.V., Rahn, H., Johnson, R.R., 1987. Influence of eggshell pore shape on gas diffusion. J. Exp. Zool. Suppl. 1, 181-186.

Touraine, F., 1960. Oeufs d’Oiseaux de très grande taille dans l'Eocène inférieur de Provence, pp. 783-789.

Tullet, G.S., 1984. The porosity of avian eggshells. Comp. Biochem. Physiol. 78A, 5-13.

Villa, J.P., 2006. http://www.expo-mineraux-nimes.fr (Nîmes, France).

Williams, D.L.G., Seymour, R.S., Kerourio, P., 1984. Structure of fossil dinosaur eggshell from the Aix basin, France. Palaeogeogr. Palaeoclimatol. Palaeoecol. 45, 23-37.

Zachos, J.C., Wara, M.W., Bohaty, S., Delaney, M.L., Petrizzo, M.R., Brill, A., Bralower, T.J., Premoli-Silva, I., 2003. A transient rise in tropical sea surface temperature during the Paleocene-Eocene thermal maximum. Science 302, 1551-1554.

Zhao, Z.K., 1975. The microstructures of the dinosaurian eggshells of Nanxiong Basin, Guangdong Province. (I) On the classification of dinosaur eggs. Vertebr. PalAsiat. 13, 105-117.

Zhao, Z.K., 1994. Dinosaur eggs in China: on the structure and evolution of eggshells. In: Carpenter, K., Hirsch, K.F., Horner, J.R. (Eds.), Dinosaur eggs and babies. Cambridge Univ. Press, pp. 184-203.

Zelenitsky, D.K., Modesto, S.P., 2003. New information on the eggshell of ratites (Birds) and its phylogenetic implications. Can. J. Zool. 81, 962-970. 